\title{
What should be the role of fractional flow reserve measurement in patients undergoing coronary artery bypass grafting?
}

\author{
David Glineur, MD, PhD, ${ }^{a}$ Aun Yeong Chong, MD, ${ }^{\mathrm{b}}$ and Juan Grau, $\mathrm{MD}^{\mathrm{a}}$
}

Feature Editor's Introduction-Glineur and colleagues from Ottawa present a superb summary on the evidence of the use of fractional flow reserve (FFR) for coronary bypass surgery.

FFR was conceived to guide percutaneous coronary interventions, a procedure that targets directly the culprit plaque and whose success is inversely related to the complexity and the numbers of the lesions treated. In this context, a tool able to identify the flow-limiting lesions and reduce the procedural complexity and the number of stents implanted makes obvious sense.

Bypass surgery is intrinsically different than percutaneous coronary interventions in 2 key aspects: surgery targets the distal, normal, or almost normal portion of the target vessel; and the procedural success of bypass surgery is not influenced by target lesion complexity. In surgery, the association between the number of treated lesions and the outcome is very weak (or nonexistent in the modern era). In this setting, the use of FFR makes much less sense, especially because the use of FFR to inform surgical grafting carries the important risk of jeopardizing 2 cornerstones of the success of coronary surgery: completeness of revascularization and protection of the coronary bed from disease progression.

I'm grateful to Dr Glineur and his group for this very articulated summary of such an important issue, and I'm sure that readers will echo my sentiment.

\section{Mario Gaudino, MD, MSCE}

The current challenge cardiac surgeons face with regard to the role of fractional flow reserve (FFR) in their field is not insignificant. The evidence behind FFR-guided percutaneous coronary intervention (PCI) is robust, based on the FAME series of trial, ${ }^{1,2}$ comparing Fractional Flow

From the Divisions of ${ }^{\mathrm{a}}$ Cardiac Surgery and ${ }^{\mathrm{b}}$ Cardiology, University of Ottawa Heart Institute, Ottawa, Ontario, Canada.

Received for publication Oct 29, 2020; accepted for publication Oct 29, 2020; available ahead of print Dec 10, 2020.

Address for reprints: David Glineur, MD, PhD, Division of Cardiac Surgery, University of Ottawa Heart Institute, 40 Ruskin St, Ottawa, Ontario K1Y 4W7 Canada (E-mail: dglineur@ottawaheart.ca).

JTCVS Open 2021;5:74-9

2666-2736

Copyright (C) 2020 The Authors. Published by Elsevier Inc. on behalf of The American Association for Thoracic Surgery. This is an open access article under the CC BY-NCND license (http://creativecommons.org/licenses/by-nc-nd/4.0/).

https://doi.org/10.1016/j.xjon.2020.10.010

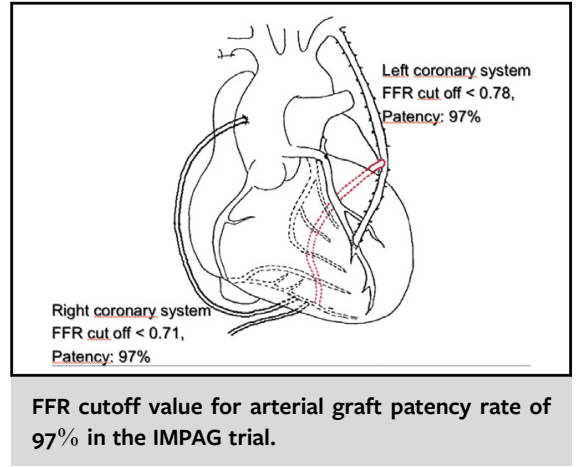

CENTRAL MESSAGE

FFR as a guide to dictate whether a patient will benefit from CABG versus $\mathrm{PCl}$ and or which vessels should or not be grafted should be discouraged. FFR is useful for graft choice (arterial vs venous).

See Commentaries on pages 80 and 83 .

Reserve versus angiographic-guided revascularization in Patients with Multivessel Coronary Artery Disease and it has become the standard of care for interventional cardiologists who currently plan their intervention based on the functional analysis of any given stenosis rather than its visual appearance in 2 dimensions at the time of coronary catheterization. They have the significant advantage of deferring and reassessing a particular lesion based on physiology. Cardiac surgeons in general are less receptive to the FFR for several reasons. First, it is not feasible to defer surgical revascularization of a borderline stenosis; second, coronary artery bypass grafting (CABG) has always been perceived to protect patients from future events by grafting moderate lesions; and third, as a surgical procedure it remains stunted in its evolution as evidenced by the use of the left internal thoracic artery and saphenous veins as the conduits of choice for the vast majority of patients.

In this article, we will discuss the issues the surround the topic of FFR in CABG by performing a careful and objective analysis of the current available data, including our own, in the literature. 


\section{METHODS TO ASSESS SEVERITY OF STENOSIS}

The most commonly used methods by surgeons to estimate the severity of the coronary stenosis and the potential for competitive flow is visual estimation. The Cleveland Clinic has extensively studied the correlation between graft patency and the percent stenosis estimated by visual inspection. They found that the best patency for internal thoracic conduits is found when they are used to bypass the left anterior descending artery (LAD) territory. In fact, the same authors observed that the severity of the LAD lesion has a low influence on internal thoracic artery patency, whereas it is on the right coronary artery territory where patency relates most with the degree of stenosis. ${ }^{3,4}$ Similarly, patency rates of radial and gastroepiploic arteries are dependent on the degree of native coronary artery stenosis. ${ }^{5}$

The physiologic way to assess the severity of a coronary stenosis is by using FFR. ${ }^{6}$ FFR was first measured invasively with a catheter across the coronary stenosis with maximal hyperemia induced by the administration of adenosine mimicking conditions similar to those experienced during stress test. Therefore, it is a ratio of pressure in a vessel distal to a stenosis of interest compared with that vessel in the absence of the stenosis, and a value $\leq 0.8$ indicates significant ischemia. More recently, instantaneous wave-free ratio has been used in planning surgical revascularization. This method has been found to be more sensitive to detect critical stenoses than FFR. ${ }^{7}$ The advantages of FFR are that it accounts for the size and amount of viable myocardium supplied by a specific diseased coronary artery, the quality of the vessels bypassed, their sizes, and the presence of distal disease (Figure 1). In the FAME sub-study trials ${ }^{8}$ and others, ${ }^{9}$ the researchers found, in concordance with the results of the Cleveland Clinic, ${ }^{3}$ that the LAD territory has the highest mismatch between percent stenosis and FFR $\leq 0.8$, showing that when looking at mild to moderate stenosis of the LAD we have the highest probability of having a positive FFR compared with other branches of the coronary tree. The circumflex artery territory has a better correlation than the LAD between the visual estimation and FFR $\leq 0.8$, but the best correlation is with the right coronary artery territory. The most common explanation is that myocardial mass supplied by the LAD is the largest compared with other territories. ${ }^{10}$

In utilizing FFR to determine whether there is inducible ischemia, its pitfalls must be recognized by practitioners. FFR is based on pressure and the assumption of maximal hyperemia. For FFR to be performed accurately and reproducibly, a correct technique is of paramount importance with special care taken to identify disengagement of the catheter guide during measurement, ${ }^{11}$ correct positioning of the pressure sensor in relation to the stenosis in question, and the achievement of maximal hyperemia. Obtaining maximal hyperemia can be influenced by something as innocuous as recent intake of caffeine by a patient.

Particularly relevant to CABG, FFR measurement of a stenosis may be significantly influenced by the presence of another downstream stenosis. This arises in the assessment of the left main coronary stenosis, whereby a downstream stenosis (eg, in the LAD) has a tendency to underestimate the severity of the left main stenosis (ie, higher FFR than actual). ${ }^{12}$ Another caveat of utilizing FFR in CABG is in the evaluation of vessels with predominantly diffuse atherosclerosis or microvascular dysfunction. In the presence of diffuse atherosclerosis, FFR is typically overestimated, resulting in a higher-than-expected FFR.

The functional SYNTAX score, using FFR to guide PCI has been proposed to target revascularization and reclassify multivessel disease based
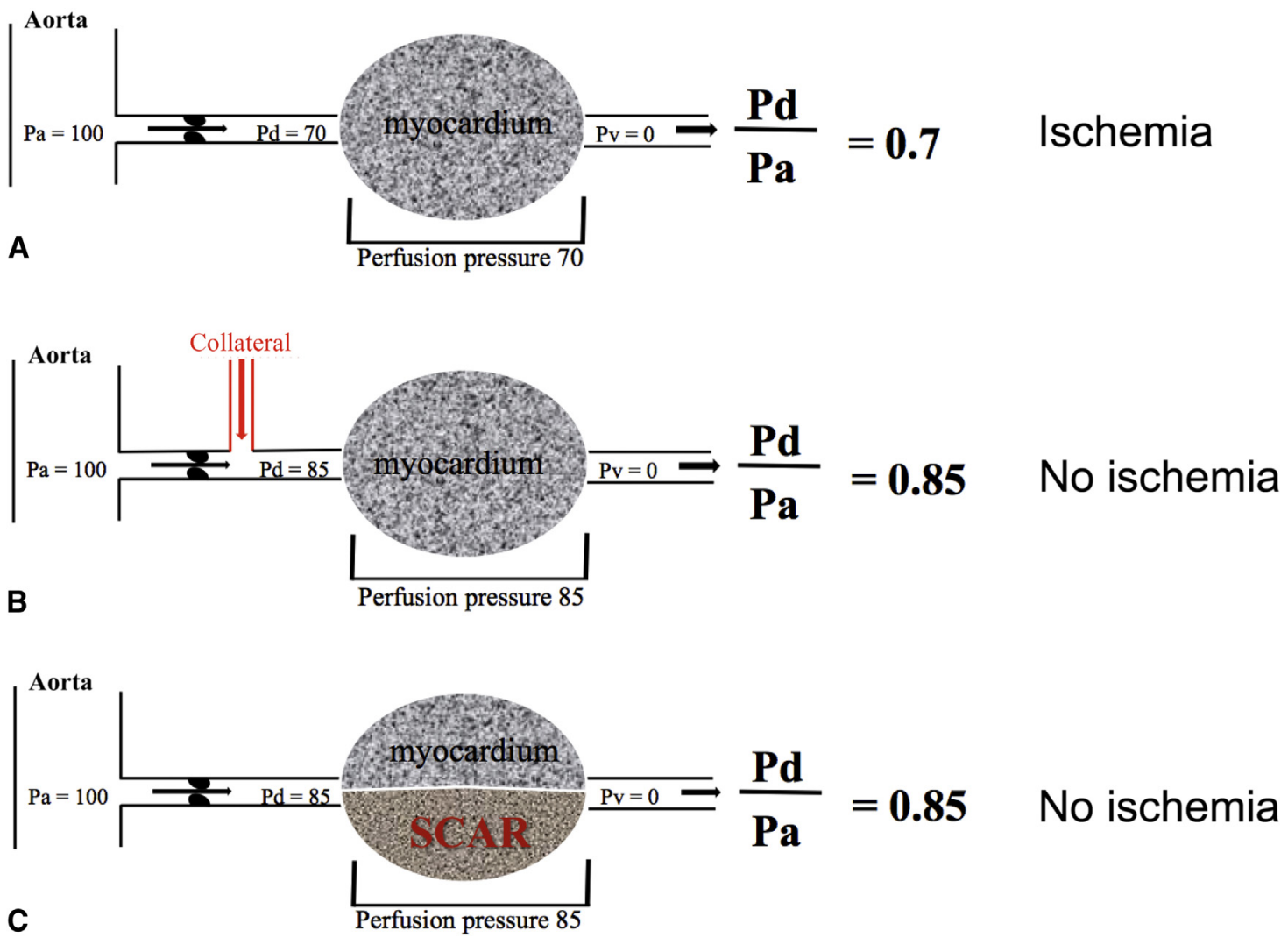

FIGURE 1. Fractional flow reserve (FFR) physiological explanation. A, Example of a lesion with a 70\% stenosis and a positive FFR of 0.7. B, Example of a lesion with a $70 \%$ stenosis with distal collateral and a negative FFR of 0.85 . C, Example of a lesion with a $70 \%$ stenosis with a myocardial scar and a negative FFR of 0.85 . 
on angiography. Although this is an attractive option, it is not feasible to defer revascularization in patients undergoing $\mathrm{CABG}$ because it is often a definitive invasive treatment unlike PCI, where further intervention could be deferred. It is also assumed that surgical revascularization protects a patient against future cardiovascular events, independent from the complexity of the underlying disease because it provides a secondary blood supply to the coronary tree. Two points remain to be addressed: Will a graft remain open when grafted to a moderately stenosed coronary lesion without evidence of functional stenosis by FFR? and, How would the 2 different types of conduits, arterial or venous, behave in this scenario? In the absence of data from randomized controlled trials, the routine use of FFR to dictate which vessel to graft or not to graft surgically remains unanswered.

\section{COMPETITIVE FLOW CONCEPT}

When performing a coronary revascularization procedure, the goal of the intervention is to restore blood supply to a myocardial territory that is ischemic through the interposition of a low-resistance conduit allowing adequate flow of blood over the area of stenosis of the involved coronary artery segment. This bypass conduit must be able to accommodate the high flow demands of systemic pressure with minimal pressure drop at the site of distal implantation reliably and for a prolonged period of time.

The phenomenon of competitive flow occurs when the resistance to the flow of blood through the coronary bypass graft closely matches that of the native coronary artery vessel. In this situation, both the bypass conduit and the coronary artery contribute to the myocardial perfusion of a given myocardial territory. In the case of vein grafts, the pressures at the 2 ends of the conduit are identical-the absence of muscular layers and their large diameter making them the perfect compliance conduits. On the other hand, when arterial grafts are used as bypass grafts, a higher pressure at the proximal aspect rather than at the site of the distal anastomosis will always be the norm for these grafts due to the smaller diameter and the higher vasomotor tone (muscular layer) of arterial conduits. In an observational study, we found 6 times higher pressure gradients drop in arterial grafts compared with venous grafts between the aorta and the distal conduit anastomosis. ${ }^{13}$ Due to these intrinsic conduit differences, competitive flow will significantly influence more arterial conduits than their venous counterparts, potentially leading to graft attrition and occlusion. This phenomenon has been widely reported in the literature $^{14-16}$ (Figure 2).

The influence of flow competition also depends on the targeted coronary artery. Indeed, arterial grafts to the LAD territory were found to better tolerate competitive flow compared with arterial conduits used to bypass the lateral or inferior walls of the heart. ${ }^{3}$

The influence of FFR results on CABG has been studied in 2 types of trials: patency trials and in outcome-driven clinical trials. These 2 different types of trials have tried to answer very different questions: Does FFR $\leq 0.8$ influence graft patency? or, Does not grafting a vessel with FFR $>0.8$ influence the clinical outcome of patients undergoing surgical coronary revascularization in a similar way to what has already been demonstrated in the cardiology literature?

\section{FFR AND GRAFT PATENCY}

Botman and colleagues ${ }^{17}$ analyzed prospectively 164 patients undergoing CABG who had FFR measured during preoperative diagnostic angiogram. At 1 year, a systematic angiographic follow-up was performed. The authors concluded that bypassing lesions with FFR $>0.75$ resulted in a greater rate of graft occlusion $(21.4 \%$ in FFR $>0.75$ vs $8.9 \%$ in FFR $<0.75 ; P<.001$ ). Honda and colleagues ${ }^{18}$ evaluated the relationship between preoperative FFR on 74 $\mathrm{LAD}$ stenosis procedures and the intraoperative bypass graft flow pattern. They divided the results into 3 groups: Group $S$ : FFR $<0.70$, group M: FFR $\geq 0.70$ but $<0.75$, and group $\mathrm{N}$ : FFR $\geq 0.75$. In groups $S, M$, and $N$, respectively, mean graft flow was $24.7,19.2$, and $16.0 \mathrm{~mL} / \mathrm{min}(P=.009)$ and pulsatility index was $2.35,3.02$, and $5.51(P=.038)$. They concluded that as coronary stenosis severity increased, graft flow increased and pulsatility index decreased. Our group recently studied the influence of FFR in total arterial composite grafting in the Impact of Preoperative FFR on Arterial Bypass Graft Functionality trial. ${ }^{19}$ Sixty-three patients underwent both coronary angiography and FFR as part of their diagnostic workup and subsequently underwent total arterial CABG. At 6 months, a systematic angiographic follow-up was performed. We found that FFR, but not angiographic stenosis severity, was a predictor of arterial graft patency and functionality at 6 months. Anastomoses performed to coronary arteries with FFR $<0.78$ had a patency rate of $97 \%$. Moreover, in a post hoc analysis, ${ }^{20}$ the same authors found that the FFR cutoff value to have a patent arterial graft is lower (0.71) when targeting the right coronary system. This finding is mainly related to the distance between the graft inflow (aorta or internal thoracic artery) and the distal coronary target, the longer the distance the higher risk for competitive flow.

\section{FFR SURVIVAL AND CLINICAL OUTCOME IN PATIENTS UNDERGOING CABG}

Toth and colleagues ${ }^{21}$ in a retrospective FFR-guided versus angiographically guided CABG found that after 3 years, FFR-guided CABG patients had a lower incidence of class II through IV angina ( $13 \%$ vs $4 \% ; P<.001)$, a lower incidence of recurrent angina, and greater freedom from saphenous vein graft occlusion. ${ }^{21}$ A second study using the same patient cohort by Fournier and colleagues ${ }^{22}$ assessed at least 1 intermediate stenosis in 627 patients by either coronary angiography alone or angiography plus FFR. The authors found that patients in the FFR-guided group had fewer anastomoses, and a lower rate of death and myocardial infarction 6 years after surgery (hazard ratio $=0.59 ; 95 \%$ confidence interval, $0.38-0.93$ ) 

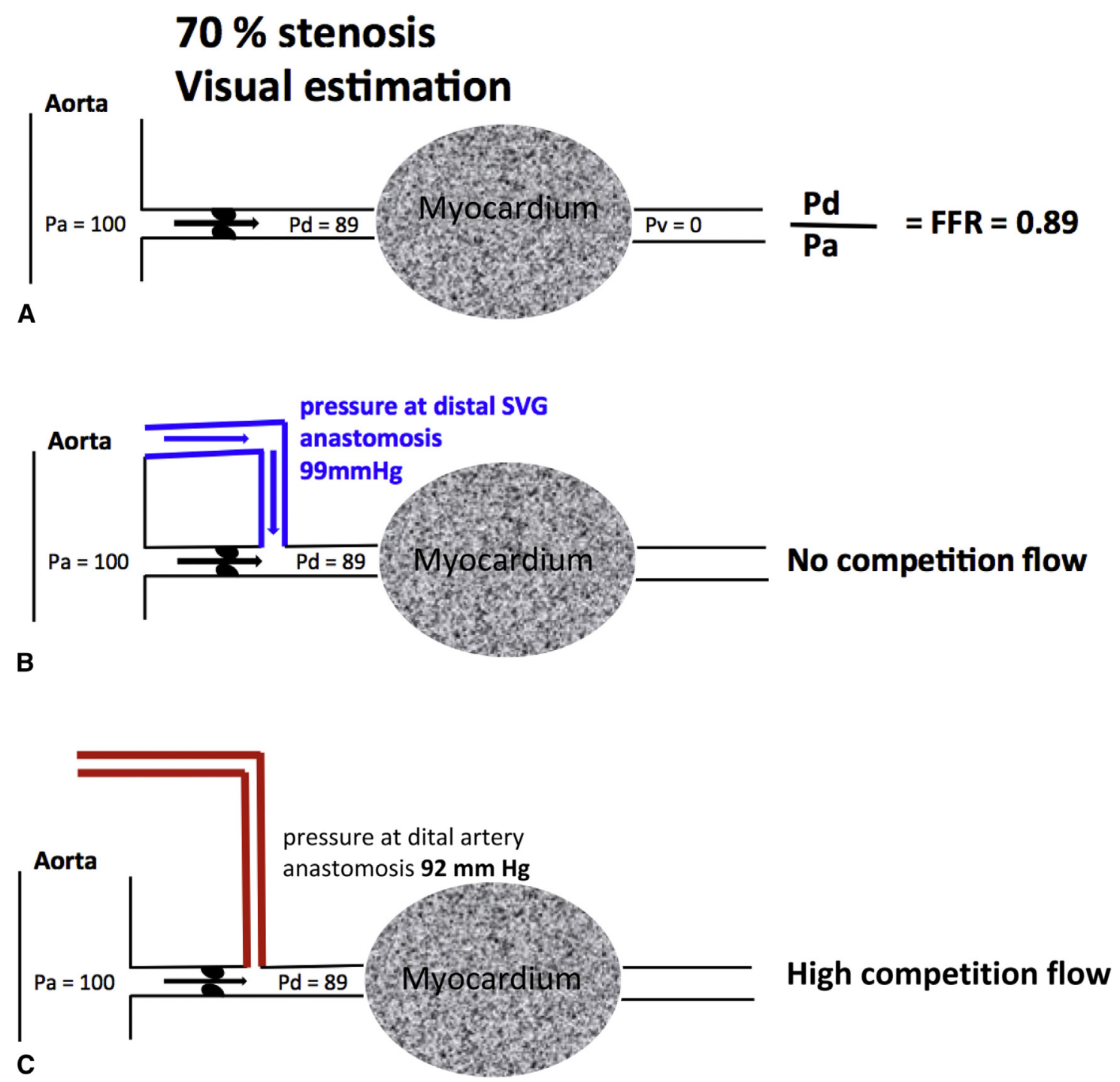

FIGURE 2. Fractional flow reserve $(F F R)$ and competition flow in a moderate stenosis: Difference between saphenous and arterial graft. A, Example of a lesion with a $70 \%$ stenosis and a negative FFR of 0.89 . B, Same example after a saphenous bypass. Absence of competition flow due to the pressure at the distal end of the vein of $99 \mathrm{~mm} \mathrm{Hg}$. C, Same example after an arterial bypass. High competition flow due to the drop of pressure at the distal end of the artery of $91 \mathrm{~mm} \mathrm{Hg.} \mathrm{SVG}$, Saphenous vein graft.

The Fractional Flow Reserve versus Angiography Randomization for Graft Optimization (FARGO) trial $^{23}$ analyzed graft patency and clinical outcomes at 6 months in 100 patients randomized to undergo angiographyguided CABG versus FFR-guided CABG. All the nonLAD grafts were veins $(75 \%)$. No patency difference was observed between the 2 groups. Moreover, there were no differences in major adverse cardiac and cerebrovascular events rate at 1 year. Several limitations of the FARGO trial warrant caution in the interpretation of the results. First, the study was stopped early at $58 \%$ of the expected enrolment. Second, $12 \%$ of patients did not receive the planned treatment, mainly owing to intraoperative technical problems. Third, the power calculation was based on a predicted rate of graft occlusion of $20 \%$ after 6 months in grafts to coronary arteries with FFR $>0.80$, and $5 \%$ with FFR $<0.80$. However, the observed rates were much lower, at $10 \%$ and $8 \%$, respectively. Lastly, the number of patients who underwent follow-up angiography was $25 \%$, which failed to reach the predicted rate of $15 \%$ established during trial design.

The Graft Patency after FFR-Guided versus Angiography-Guided CABG (GRAFFITI) trial ${ }^{24}$ investigated the influence of FFR on graft patency and clinical outcomes. One hundred seventy-two patients were randomized to angiography-guided or FFR-guided CABG. The ratio of arterial to venous grafts used was 1:1. At 1-year follow-up, no difference in overall graft patency or in major adverse 
cardiac and cerebrovascular events was found. Several limitations of the GRAFFITI trial should be carefully considered when interpreting the results. First, although the expected loss to follow-up was $20 \%$, angiographic control at 1 year was performed in only $65 \%$ of patients. Second, surgical protocol violation due to surgeons' reluctance to base their surgical strategy on FFR might have decreased the significance of FFR guidance in the trial; indeed, in the FFR-guided group, $29 \%$ of the deferred vessels had FFR $<0.80$ and $11 \%$ of bypassed vessels had FFR $>0.80$. Third, the trial was underpowered for both clinical and angiographic outcomes. Due to slow enrollment, the GRAFFITI trial was stopped at $83 \%$ of the sample size.

\section{WHAT CAN WE CONCLUDE FROM THESE STUDIES?}

Most of the data addressing FFR in CABG come from retrospective, single-center studies with small sample sizes and short follow-up. In terms of graft patency, data from the Impact of Preoperative FFR on Arterial Bypass Graft Functionality trial, ${ }^{19}$ Botman and colleagues,${ }^{17}$ and Honda and colleagues, ${ }^{18}$ contradict the findings from FARGO $^{23}$ and GRAFFITI trials. ${ }^{24}$ Occlusion rate in the 2 prospective randomized trials ${ }^{23,24}$ reached $16 \%$ to $20 \%$ at 1 year without difference between the 2 groups, whereas in the full arterial grafting trial it was $3 \%$ when FFR was $<0.78$. The explanation for this significant difference is probably related to the difference in the types of graft used in the different trials. We have described above how and why saphenous veins are not sensitive to competition flow when compared with arterial grafts. In terms of clinical outcomes-knowing that the 2 trials were very largely underpowered with significant bias-no clinical benefit of FFRbased CABG was observed.

The functional SYNTAX score uses FFR to downgrade the severity of coronary artery disease and it has been proposed by many cardiologists to simplify the revascularization procedure. The transference of this concept to CABG is, today, not supported by scientific evidence. Indeed, the goal of surgical revascularization has always been to protect the patient from future events independently of the complexity of the underlying disease. Moreover, the residual SYNTAX score after revascularization is a strong predictive indicator of long-term survival and major adverse cardiac and cerebrovascular events. ${ }^{25}$ The use of FFR could increase the rate of anatomic incomplete revascularization with potential deleterious long-term consequence for our patients.

\section{CONCLUSIONS}

Based on the current evidence and the absence of data from larger trials powered to detect differences in clinical outcomes, the use of FFR as the only guide to dictate whether a patient should become a candidate for a surgical revascularization strategy versus PCI and or which vessels should or not be grafted should be discouraged. However, FFR seems to be an important tool to help decide which type of graft to use (ie, arterial for lesions with an FFR $<0.78$, venous for those with higher values).

\section{Conflict of Interest Statement}

The authors reported no conflicts of interest.

The Journal policy requires editors and reviewers to disclose conflicts of interest and to decline handling or reviewing manuscripts for which they may have a conflict of interest. The editors and reviewers of this article have no conflicts of interest.

\section{References}

1. Tonino PA, De Bruyne B, Pijls NH, Siebert U, Ikeno F, van't Veer M, et al. Fractional flow reserve versus angiography for guiding percutaneous coronary intervention. N Engl J Med. 2009;360:213-24.

2. Tonino PA, Fearon WF, De Bruyne B, Oldroyd KG, Leesar MA, Ver Lee PN, et al. Angiographic versus functional severity of coronary artery stenoses in the FAME study fractional flow reserve versus angiography in multivessel evaluation. J Am Coll Cardiol. 2010;55:2816-21.

3. Sabik JF III, Olivares G, Raza S, Lytle BW, Houghtaling PL, Blackstone EHJ Does grafting coronary arteries with only moderate stenosis affect long-term mortality? Thorac Cardiovasc Surg. 2016;151:806-11.

4. Sabik JF III, Blackstone EH. Coronary artery bypass graft patency and competitive flow. J Am Coll Cardiol. 2008;51:126-8.

5. Gaudino M, Alessandrini F, Pragliola C, Cellini C, Glieca F, Luciani N, et al. Effect of target artery location and severity of stenosis on mid-term patency of aorta-anastomosed vs. internal thoracic artery-anastomosed radial artery grafts. Eur J Cardiothorac Surg. 2004;25:424-8.

6. Pijls NH, De Bruyne B, Peels K, Van Der Voort PH, Bonnier HJ, Bartunek J, et al. Measurement of fractional flow reserve to assess the functional severity of coronary-artery stenoses. N Engl J Med. 1996;334:1703-8.

7. Baibhav B, Gedela M, Moulton M, Pavlides G, Pompili V, Rab T, et al. Role of invasive functional assessment in surgical revascularization of coronary artery disease. Circulation. 2018;137:1731-9.

8. Toth G, Hamilos M, Pyxaras S, Mangiacapra F, Nelis O, De Vroey F, et al. Evolving concepts of angiogram: fractional flow reserve discordances in 4000 coronary stenoses. Eur Heart J. 2014;35:2831-8.

9. Watanabe H, Onishi K, Kakehi K, Takase T, Yamaji K, Ueno M, et al. Clinical and angiographic factors predicting fractional flow reserve and explaining the visual-functional mismatch in patients with intermediate coronary artery stenosis. Coron Artery Dis. 2020;31:73-80.

10. Nordlund D, Heiberg E, Carlsson M, Frund ET, Hoffmann P, Koul S, et al. Extent of myocardium at risk for left anterior descending artery, right coronary artery, and left circumflex artery occlusion depicted by contrast-enhanced steady state free precession and $\mathrm{T} 2$-weighted short tau inversion recovery magnetic resonance imaging. Circ Cardiovasc Imaging. 2016;9:e004376.

11. Aminian A, Dolatabadi D, Lefebvre P, Khalil G, Zimmerman R, Michalakis G, et al. Importance of guiding catheter disengagement during measurement of fractional flow reserve in patients with an isolated proximal left anterior descending artery stenosis. Catheter Cardiovasc Interv. 2015;85:595-601.

12. Yong AS, Daniels D, De Bruyne B, Kim HS, Ikeno F, Lyons J, et al. Fractional flow reserve assessment of left main stenosis in the presence of downstream coronary stenoses. Circ Cardiovasc Interv. 2013;6:161-5.

13. Glineur D, Poncelet A, El Khoury G, D'hoore W, Astarci P, Zech F, et al. Fractional flow reserve of pedicled internal thoracic artery and saphenous vein grafts 6 months after bypass surgery. Eur J Cardiothorac Surg. 2007;31:376-81.

14. Sabik JF III, Lytle BW, Blackstone EH, Khan M, Houghtaling PL, Cosgrove DM. Does competitive flow reduce internal thoracic artery graft patency? Ann Thorac Surg. 2003;76:1490-6.

15. Glineur D, D'hoore W, de Kerchove L, Noirhomme P, Price J, Hanet C, et al. Angiographic predictors of 3-year patency of bypass grafts implanted on the right coronary artery system: a prospective randomized comparison of gastroepiploic artery, saphenous vein, and right internal thoracic artery grafts. J Thorac Cardiovasc Surg. 2011;142:980-8. 
16. Glineur D, D'hoore W, El Khoury G, Sondji S, Kalscheuer G, Funken JC, et al. Angiographic predictors of 6-month patency of bypass grafts implanted to the right coronary artery a prospective randomized comparison of gastroepiploic artery and saphenous vein grafts. J Am Coll Cardiol. 2008;51:120-5.

17. Botman CJ, Schonberger J, Koolen S, Penn O, Botman H, Dib N, et al. Does stenosis severity of native vessels influence bypass graft patency? A prospective fractional flow reserve-guided study. Ann Thorac Surg. 2007;83:2093-7.

18. Honda K, Okamura Y, Nishimura Y, Uchita S, Yuzaki M, Kaneko M, et al. Graft flow assessment using a transit time flow meter in fractional flow reserve-guided coronary artery bypass surgery. J Thorac Cardiovasc Surg. 2015;149:1622-8.

19. Glineur D, Grau JB, Etienne PY, Benedetto U, Fortier JH, Papadatos S, et al. Impact of preoperative fractional flow reserve on arterial bypass graft anastomotic function: the IMPAG trial. Eur Heart J. 2019;40:2421-8.

20. Glineur D, Rahouma M, Grau JB, Etienne PY, Fortier JH, Papadatos S, et al. Cutoff by arterial graft configuration and location: IMPAG trial insights. JACC Cardiovasc Interv. 2020;13:143-4.

21. Toth G, De Bruyne B, Casselman F, De Vroey F, Pyxaras S, Di Serafino L, et al. Fractional flow reserve-guided versus angiography-guided coronary artery bypass graft surgery. Circulation. 2013;128:1405-11.
22. Fournier S, Toth GG, De Bruyne B, Johnson NP, Ciccarelli G, Xaplanteris P, et al. Six-year follow-up of fractional flow reserve-guided versus angiography-guided coronary artery bypass graft surgery. Circ Cardiovasc Interv. 2018;11:e006368.

23. Thuesen AL, Riber LP, Veien KT, Christiansen EH, Jensen SE, Modrau I, et al. Fractional flow reserve versus angiographically guided coronary artery bypass grafting. J Am Coll Cardiol. 2018;72:2732-43.

24. Toth GG, De Bruyne B, Kala P, Ribichini FL, Casselman F, Ramos R, et al. Graft patency after FFR-guided versus angiography-guided coronary artery bypass grafting: the GRAFFITI trial. EuroIntervention. 2019;15: e999-1005.

25. Melina G, Angeloni E, Refice S, Benegiamo C, Lechiancole A, Matteucci M, et al. Residual SYNTAX score following coronary artery bypass grafting. Eur J Cardiothorac Surg. 2017;51:547-53.

Key Words: fractional flow reserve, coronary artery bypass grafting, arterial graft, flow competition 